REVISTA X, Curitiba, volume 12, n.3, p.152-177,2017.

\title{
DESLOCAMENTOS LINGUÍSTICOS E SUBJETIVOS NA APRENDIZAGEM DA LÍNGUA INGLESA POR MEIO DO TEATRO E DE SUAS TÉCNICAS ${ }^{1}$
}

\author{
Linguistic And Subjective Displacements In The Learning Of English Through \\ Drama And Its Techniques
}

\author{
Valdeni da Silva REIS - UFMG ${ }^{2}$ \\ Yedda Soares COSTA - UFVJM ${ }^{3}$
}

\begin{abstract}
RESUMO: O presente trabalho pretende analisar os impactos e os desdobramentos do ensino da Língua Inglesa (LI) por meio do teatro e de suas técnicas. Durante quase quatro meses, aulas semanais de LI foram ministradas utilizando recursos teatrais. Entrevistas iniciais e finais foram realizadas na língua-alvo com os participantes da pesquisa para análise do desenvolvimento linguístico. Relatos escritos pelos participantes foram também coletados e analisados ao final de cada aula. Os resultados indicam que, além de aprender e aprimorar a LI, principalmente no que se refere ao desenvolvimento do vocabulário e da pronúncia, o teatro fez com que os participantes perdessem o medo (de errar) e se arriscassem a falar usando a LI, proporcionando deslocamentos na constituição subjetiva do aluno. Pode-se concluir, portanto, que o uso do teatro como estratégia pedagógica para o ensino da LI é uma técnica que pode contribuir para o processo de aprendizagem, promover a motivação e levar ao deslocamento subjetivo dos alunos.
\end{abstract}

PALAVRAS-CHAVE: Ensino da LI; Teatro; Técnicas teatrais; Deslocamentos subjetivos; Desenvolvimento linguístico.

ABSTRACT: This paper aims to analyze the impacts and the implications of the teaching of English through drama and its techniques. For almost four months, classes of English were weekly taught through the use of drama techniques. Initial and final interviews with the participants were conducted in English in order to analyze their development. Reports written by the participants were also collected and analyzed at the end of each class. The results point out that, in addition to the development of English, especially concerning the vocabulary and pronunciation improvement, the use of drama led the participants to lose the fear (of making mistakes) they had, and also encouraged them to take the risk and use English, fostering displacements in their subjective constitution. To conclude, the use of drama as a pedagogical strategy for the teaching of English is a technique that can contribute to the learning process, foster motivation and lead to students' subjective displacement.

\footnotetext{
1 Trabalho realizado com o apoio da Fundação de Amparo à Pesquisa do Estado de Minas Gerais (FAPEMIG).

${ }^{2}$ Professora Adjunta (Linguística Aplicada - Inglês) da Faculdade de Letras da Universidade Federal de Minas Gerais e do Programa de Pós-Graduação em Estudos Linguísticos (POSLIN). Doutora em Linguística Aplicada pela UFMG.

3 Graduanda em Letras Português / Inglês pelo Centro Educacional Claretiano.
} 
KEYWORDS: English learning; Drama; Drama techniques; Subjective Displacements; Language development.

\section{INTRODUÇÃO}

A relação do teatro com o ensino vem sendo estabelecida há milênios. Segundo Figueiredo (2009), o teatro está presente na educação desde a antiguidade, passando por diferentes contextos e redefinições. As primeiras referências ao uso do teatro para fins educativos podem, portanto, ser encontradas já nas primeiras civilizações (HANSTED, 2013). Os gregos utilizavam técnicas teatrais, como uso de expressões faciais e de gestos dramáticos, para representação em aulas de literatura para declamação de poesias (HANSTED, 2013).

No Brasil, os primeiros indícios da utilização do teatro para fins educativos são encontrados a partir da chegada dos portugueses. O teatro foi então utilizado como método para catequização dos índios pelos jesuítas, a fim de lhes ensinar a fé e os mandamentos religiosos (SANTANA, 2002).

No campo do ensino da língua estrangeira (LE), a utilização do teatro já acontecia no Brasil antes da década de 70 (MESKELL; SANDER, 1976). Segundo os autores, técnicas teatrais, como leitura ou representação dramática de diálogos ou de cenas maiores, têm estado presentes em nossas salas de aula desde muito tempo. Mesmo que timidamente, tais técnicas têm sido utilizadas há décadas para desenvolver a fluência oral dos alunos e para tornar as aulas mais dinâmicas (MESKELL; SANDER, 1976).

Contudo, o teatro passa a ganhar mais espaço na sala de aula de LE a partir do surgimento e da disseminação da Abordagem Comunicativa no final dos anos 1970. Nessa abordagem, as atividades significativas e comunicativas passam a ser enfatizadas, em detrimento das atividades mecânicas de simples repetição e memorização (SAM, 1990). A Abordagem Comunicativa leva para o contexto da sala de aula uma nova concepção de ensino-aprendizagem do inglês como LE. O aluno passa a ser enxergado como um participante ativo e fundamental no processo de aprendizagem na sala de aula, enquanto o professor, facilitador desse processo, passa a ser responsável pela promoção de atividades que estimulem uma aprendizagem cada vez mais autônoma e dinâmica, por meio da inclusão de atividades em grupo com interações significativas. 
Podemos afirmar, então, que a Abordagem Comunicativa se caracteriza por ter o foco no sentido, no significado e na interação propositada entre os sujeitos que estão aprendendo uma nova língua (ALMEIDA FILHO, 1993). Parte dessa interação é promovida com a integração da sala de aula com situações do mundo real, levando o aluno a comunicar-se na língua alvo, representando personagens em situações fíctícias com a dramatização. Percebemos, assim, que a Abordagem Comunicativa impulsionou, de algum modo, a utilização do teatro e de seus jogos na sala de aula de língua estrangeira (LE), por meio da criação de tais atividades comunicativas de improviso e dramatização contidas principalmente nos role-playing games $(R P G)^{4}$.

O presente trabalho discute os principais aspectos de um projeto tríade pesquisaensino-extensão, cujo objetivo central é o ensino da língua inglesa (LI) por meio de técnicas teatrais. De modo mais específico, investigamos os impactos do uso do teatro para o desenvolvimento linguístico do aluno e para eventuais processos de deslocamentos subjetivos dos envolvidos, sendo essa a nossa maior contribuição para o campo de ensino de línguas estrangeiras. Defendemos, portanto, que, ao ser convocado a reinventar-se a partir de personagens, textos e situações, o sujeito pode despir-se de antigas amarras que o impedem de se descobrir na aprendizagem da LI, tornando-se capaz de se dizer, ou seja, de colocar-se no mundo, reinventando sua identidade e história de aprendizagem.

Neste sentido, para a realização desse trabalho, procuramos responder às seguintes perguntas:

1. Quais são os impactos da utilização do teatro e suas técnicas para a aprendizagem da LI?

2. Como essa experiência é significada pelo sujeito aprendiz?

Ao longo das seções que se seguem, discutiremos a teoria que embasa nossa proposta, detalharemos a metodologia empregada no estudo, bem como os resultados e o modo como eles respondem as perguntas de pesquisa expostas anteriormente.

\section{FUNDAMENTAÇÃO TEÓRICA}

\footnotetext{
${ }^{4}$ Atividade comum nas aulas de línguas. Significa a representação em inglês de cenas curtas ou situações corriqueiras como ir ao banco ou comprar uma roupa. Para apresentação e estudo detalhados, consulte Morais (2014), Islam e Islam (2012), Aliakbari e Jamalvandi (2010), Kumbartzki-Ferreira (2008), Livingstone (1983), entre outros.
} 
Com a criação do método de "aprender fazendo" contido no livro Educational principles, John Dewey inova o ensino por meio do uso de dramatizações para a aprendizagem das crianças em escolas americanas no início do século passado (TAVARES, 2004). Em 1917, Caldwell Cook formalizou o uso de dramatizações como método educacional com a sua obra "The Play Way" (COÊLHO, 2010). Tal método, salienta a autora, tinha como fundamento ensinar a língua inglesa como LE por meio da dramatização, preparando o aluno para o mundo real.

Assim, apontamos que, na aprendizagem de uma língua estrangeira (LE), especificamente o inglês, o teatro pode revelar-se como fator que contribui para a construção de ambientes reais de comunicação, desenvolvendo a habilidade linguística para a prática de produção oral e escrita (MENEZES et al., 2012). Ao mesmo tempo, a utilização de textos teatrais para o ensino da LE pode despertar no aprendiz o prazer pela leitura, levando-o a construir um mundo fictício, mas igualmente profundo, a partir do qual ele descobrirá formas novas de sentir, viver, aprender e compreender a realidade na qual está inserido (OLIVEIRA; FARIAS; FARIAS 2013).

Dessa maneira, o teatro pode ser visto como ferramenta que permite ao aluno desenvolver sua criatividade e autoestima, ao passo que também proporciona elementos para construir seus conhecimentos a partir de interações e reflexões sobre a prática realizada (COÊLHO, 2010). De acordo com Souza (2013), as técnicas dramáticas fornecem elementos que potencializam o aprendizado de LE, como segurança, motivação e iniciativa. Assim, a associação do teatro ao ensino da LI pode representar uma abordagem coerente e adequada para levar o aprendiz a desenvolver-se de maneira mais ampla, ativa e emancipatória, redefinindo a sua identidade e ampliando sua própria cultura (SOUZA, 2013).

Além disso, o uso do teatro e de suas técnicas para o ensino da LI convoca o aluno a colocar a si próprio e o outro em uma situação imaginária, o que lhe dá a oportunidade ímpar de se fazer presente por meio de expressões orais e corporais, exercitando sua memória e imaginação criativa (HOLDEN, 1981). Mais que isso, o envolvimento do aprendiz com textos, falas, técnicas e diferentes personagens pode fazer com que ele se descubra ou se (re)defina a partir de um novo olhar e uma nova forma de aprender a LI e de colocar-se no mundo, redefinindo papéis e identidades. 
Dentro dessa perspectiva, Revuz (1998, p. 227) permite-nos compreender que “aprender uma língua é sempre, um pouco, tornar-se um outro". Ao aventurar-se na aprendizagem de uma língua estrangeira, o sujeito confronta-se com outras formas de ver-se e de relacionar-se com o mundo. Percebemos, com isso, que o sujeito, em sua aprendizagem por meio do teatro e de suas técnicas, vislumbra a possibilidade quase que palpável de (re)inventar outras formas de seu eu, ao passo que a língua (estrangeira) ganha força e forma dentro dele. Corpo e língua revelam-se indissociáveis e importantes para que os participantes aprendam a visitar o desconhecido e o estranho, arriscando e entendendo que arriscar e errar são partes indispensáveis do processo de aprendizagem. Segundo Revuz (1998, p. 216-217):

Objeto de conhecimento intelectual, a língua é também objeto de uma prática. Essa prática é, ela própria, complexa. Prática de expressão, mais ou menos criativa, ela solicita o sujeito, seu modo de relacionar-se com os outros e com o mundo; prática corporal, ela põe em jogo todo o aparelho fonador. (...). O sujeito deve pôr a serviço da expressão de seu eu um vaivém que requer muita flexibilidade psíquica entre um trabalho de corpo sobre os ritmos, os sons, as curvas entoacionais, e um trabalho de análise e de memorização das estruturas linguísticas.

Revuz (1998) defende que a aprendizagem de uma língua perpassa o corpo. O teatro e suas técnicas, da mesma forma, requerem o corpo e as diversas expressões do eu como elementos fundamentais para sua realização. Temos, portanto, instâncias distintas, sendo elas a aprendizagem de línguas e o teatro, que convocam o corpo em seus processos, mobilizando a forma como seu sujeito se constitui. Concordamos com Coracini (2007, p. 152) quando a autora afirma que:

\begin{abstract}
A língua chamada estrangeira tem uma função formadora, atuando diretamente na imagem de nós mesmos e dos outros, na constituição identitária do sujeito do inconsciente. Ainda que seja aprendida com um fim meramente utilitarista, ela traz sempre consigo consequências profundas e indeléveis para a constituição do sujeito: serão sempre outras vozes, outras culturas, outra maneira de organizar o pensamento, outro modo de ver o mundo e o outro, vozes que se cruzam e se entrelaçam no inconsciente do sujeito, provocando reconfigurações identitárias, rearranjos subjetivos, novos saberes - não tão novos para serem originais nem tão velhos que não possam ser criativos.
\end{abstract}

Defendemos que, tanto no teatro quanto na aprendizagem de LE, o sujeito é impelido a abandonar um pouco de si na experiência, conquistando, paradoxalmente, novas possibilidades de ser e de se dizer; ele se reinventa ao se abandonar e se descobre ao se deparar com os (seus) outros. 
Além disso, de acordo com Fernandez e Coil (1986), o teatro encoraja o aluno a exercitar sua sensibilidade e emoção, tornando, portanto, a aprendizagem mais realista e significativa. Como um instrumento educacional, o uso do teatro provoca o desenvolvimento social, intelectual e linguístico do aluno (DOUGILL, 1987). O teatro e suas práticas são vistos como instrumentos que promovem o senso de responsabilidade e cooperação entre os alunos, já que as atividades são realizadas em grupos com papéis definidos, convocando uma participação ativa de todos os envolvidos (EARLY; TARLINGTON, 1983; MORDECAI, 1985).

Com isso, entendemos que levar o teatro e suas técnicas para o contexto do ensino-aprendizagem pode ser uma maneira promissora de fomentar o uso contextualizado da LI em suas quatro habilidades linguísticas, por meio da leitura, da escrita, da fala e da escuta de diálogos prontos e decorados ou a partir da dinâmica da interação ou de improvisos durante as aulas. Segundo Whiteson (1996), o improviso, elemento importante no exercício teatral, oferece aos alunos oportunidades de desenvolver suas habilidades comunicativas por meio de situações autênticas e dinâmicas. Assim, o teatro tem o poder de tornar a experiência de aprendizagem divertida e inesquecível, uma vez que ele é interativo e extremamente visual, o que potencializa seu efeito e eficiência (BOUDREAULT, 2010).

Boudreault (2010) defende que o uso do teatro para o ensino de LI possibilita uma aprendizagem que acontece a partir do uso da língua, o que nos garante uma experiência de aprendizagem instigante e prática. A língua pode ser, portanto, utilizada de forma contextualizada, ganhando vida e verdade por meio da vivência teatral e tornando a aprendizagem mais natural e efetiva. Nesse sentido, aprende-se a língua-alvo à medida que, pela necessidade, usa-se essa língua na seleção e leitura de textos, na contextualização e adaptação de textos, cenas ou músicas, na discussão, nos jogos teatrais, nos ensaios e, por fim, na própria encenação.

Maley e Duff (1982) argumentam, por sua vez, que o uso do teatro para ensino da LI contribui para a aquisição de vocabulário, motiva e constrói a confiança do aluno e favorece que o foco da aprendizagem seja no aluno, e não no professor. Nesse sentido, a situação especial de comunicação do teatro provoca demandas consideráveis na prática do professor, dada a imprevisibilidade dessa vivência ímpar (KAO, 1998). 
Mediar tal processo constitui-se, portanto, um instigante desafio que exige do professor alto investimento de tempo e de formação.

Como apontado no início do presente trabalho, a utilização do teatro para o ensino da LI no Brasil não é algo recente ou inédito. Muitos estudos já discutiram sobre o papel do teatro para o desenvolvimento da motivação e da habilidade oral do aluno (MESKELL; SANDER, 1976; DINIZ, 1996; SOUZA, 2013). Há também trabalhos que investigam professores em formação inicial diante da possibilidade do uso do teatro como ferramenta metodológica para o ensino da LI (COÊLHO, 2010; BORK, 2005; TELLES, 1991).

Nosso estudo pretende corroborar os estudos citados ao longo da presente seção, principalmente no que tange à influência do uso do teatro para o desenvolvimento linguístico do aluno em aulas de LI. Ao mesmo tempo, a presente proposta também visa contribuir para a discussão do modo como o uso do teatro para ensinar LI provoca deslocamentos subjetivos nos alunos envolvidos. Com essa ferramenta metodológica, que é detalhada na próxima seção, acreditamos que o aluno de LI é levado a se descobrir outro por meio do teatro e tem a oportunidade de reinventar sua história de aprendizagem dessa língua e seu modo de constituir-se como sujeito nela.

\section{METODOLOGIA DA PESQUISA}

Conforme apontado anteriormente, a realização da presente pesquisa foi associada a um curso de extensão, cuja carga horária era de quarenta e cinco horas, em uma universidade federal do interior do estado de Minas Gerais. As aulas eram semanais com duração de três horas, totalizando quinze encontros. Como parte da metodologia para formulação e desenvolvimento do curso de extensão, o planejamento das aulas de ensino da língua inglesa foi feito com base em técnicas teatrais, isto é, a partir de exercícios e técnicas vocais, de relaxamento, de concentração, de improvisação e de interpretação. Ministradas na LI, as aulas eram sempre iniciadas com técnicas de relaxamento e depois vocais, seguidas de atividades de expressão corporal e trabalhos de interpretação com textos e músicas em LI. Desse modo, os alunos eram levados a explorar as quatro habilidades linguísticas da LI, interagindo durante os encontros, lendo textos ou assistindo a cenas em LI e elaborando ou adaptando textos e músicas para improvisações e interpretações na língua-alvo. 
O tópico linguístico ou gramatical era trabalhado a partir da necessidade trazida pelo material de apoio para os exercícios de interpretação. Como exemplo ${ }^{5}$, a música 'Say my name' (Destiny's Child) motivou, entre outras coisas, o ensino dos cumprimentos, do vocabulário para apresentação de pessoas que acabam de se conhecer ou se encontram casualmente e do presente simples. Já com as cenas e com a trilha sonora do filme 'O casamento de meu melhor amigo' (P. J. Hogan), enfatizamos o uso do passado simples, entre muitos outros aspectos.

Após período de divulgação e inscrição para o curso (gratuito), 28 alunos da universidade e da comunidade externa foram selecionados por meio de uma entrevista. Os critérios para a seleção foram: 1) interesse do aluno pela LI e pelo teatro e 2) disponibilidade para participar das aulas do curso que eram nas tardes de quartas-feiras, das $14 \mathrm{~h}$ às $17 \mathrm{~h}$.

Os alunos selecionados formavam um grupo heterogêneo, com 16 alunas e doze alunos, com idade variando entre 17 e 35 anos. A maioria deles eram alunos universitários que estavam em diferentes períodos dos mais diversos cursos na universidade mencionada. No entanto, havia também uma aluna que ainda cursava o ensino médio na comunidade externa, uma aluna do mestrado na área da saúde da mesma universidade e um fisioterapeuta já formado. A professora do curso, também professora de língua inglesa e ensino no curso de graduação em Letras da mesma universidade, possui formação e registro profissional de atriz e experiência com as artes cênicas.

Como instrumentos de pesquisa, adotamos entrevistas no início e ao final da pesquisa e também relatos escritos pelos participantes. As entrevistas foram feitas individualmente, gravadas em áudio e transcritas posteriormente. As perguntas foram realizadas em inglês para que pudéssemos comparar a produção linguística dos participantes da pesquisa nos dois momentos. Após cada uma das duas entrevistas, isto é, entrevistas inicial e final, o aluno atribuiu uma nota para sua proficiência em língua inglesa, variando de 0 a 5 , sendo o valor zero indicador de conhecimento nulo ou irrisório e o valor cinco correspondente ao nível avançado de produção e compreensão

\footnotetext{
${ }^{5}$ Respeitando tempo, espaço e objetivos dentro dos quais o presente trabalho está concebido, não nos ateremos aqui às especificidades ou detalhamento de cada uma das 15 aulas do curso de inglês por meio do teatro e de suas técnicas.
} 
em LI. Assim, poderíamos perceber e discutir a percepção do próprio aluno acerca do impacto da intervenção para a sua aprendizagem/proficiência.

Utilizamos as mesmas perguntas (Anexo 2) em ambas as entrevistas. Entretanto, na entrevista final, também solicitamos que o aluno falasse sobre a experiência vivida por ele no curso, para analisarmos como ele interpretou o que aconteceu no decorrer do período e como o curso influenciou sua aprendizagem. Foram gerados, portanto, 250 relatos escritos pelos participantes da pesquisa. As perguntas que fomentavam o relato (Anexo 3) eram feitas em português e o aluno era orientado a utilizar a língua que desejasse, isto é, o inglês, o português ou ambas, para escrever sobre a aula que tinham participado. Para o presente trabalho, consideramos apenas os relatos escritos pelos concluintes do curso (18 alunos), totalizando duzentos e vinte (220) relatos. Descartamos, assim, relatos e entrevistas dos 10 alunos desistentes ao longo do processo e determinamos os 18 alunos concluintes como nosso grupo focal.

Para dar suporte à validade dos resultados obtidos com o grupo participante da pesquisa (grupo focal), utilizamos as mesmas perguntas do Anexo 2 para entrevistar 8 alunos universitários que cursavam a disciplina Língua Estrangeira/Inglesa II $^{6}$ (Bacharelado em Humanidades/Letras) no semestre em que a pesquisa foi desenvolvida. Desse modo, esse grupo de alunos universitários atuou como o grupo controle, cujos resultados seriam então comparados com os resultados do grupo focal. Portanto, os alunos de língua inglesa da universidade não seriam submetidos no ensino da LI por meio do teatro. Nosso objetivo era comparar a proficiência e o desenvolvimento linguístico dos alunos regulares com a proficiência e o desenvolvimento linguístico dos alunos que tiveram aulas de inglês usando o teatro, avaliando as entrevistas inicial e final de ambos os grupos ${ }^{7}$.

As entrevistas inicial e final realizadas com cada participante foram gravadas em áudio pela coordenadora da pesquisa e por uma bolsista da Iniciação Científica e foram

\footnotetext{
${ }^{6}$ Não nos é possível, nem é nosso objetivo, apresentar as especificidades do curso regular realizado por esses alunos. Não investigamos, portanto, qualquer aspecto do modo como as aulas desse grupo aconteceram. Ressaltamos que a professora do curso de extensão e coordenadora da pesquisa não era a mesma do curso regular.

${ }^{7}$ Conforme explicitado anteriormente, o grupo focal era bem diverso em suas características gerais, como idade, formação, sexo, mas também no nível linguístico apresentado por cada um. Em contrapartida, decidimos também acompanhar um grupo controle apenas como referência para nossos achados. Naturalmente, entendemos que há, neste caso, variáveis incontroláveis, mas precisávamos ter alguma referência de desenvolvimento linguístico de grupos diferentes dentro de um mesmo período de tempo.
} 
transcritas segundo um sistema de convenção de sinais (Anexo 1). As entrevistas iniciais foram concedidas por 28 participantes, totalizando mais de cinco horas de gravação. As entrevistas finais foram realizadas por 18 alunos, totalizando mais de três horas de gravação. As gravações das entrevistas inicial e final do grupo controle, isto é, o grupo de alunos que não participavam do curso que integrava inglês e teatro, totalizavam oito gravações de cerca de duas horas em cada um dos dois momentos (inicial e final).

Desse modo, a presente pesquisa é de base qualitativa e interpretativista segundo a natureza de seus dados e foram utilizados procedimentos quantitativos descritivos para alcançar resultados por meio de gráficos e tabelas. Adotamos princípios e procedimentos da análise de discurso pecheutiana (PECHÊUX, 1995; 1997) no intuito de encontrar, no dito, aquilo que também é silenciado e as marcas do sujeito que se constitui pela linguagem. Ademais, analisamos os modos de enunciar estabelecidos nos relatos e nas entrevistas por meio da categoria de análise denominada ressonância discursiva (SERRANI-INFANTE, 2001). Com base no estudo relatado pela autora, entendemos que há ressonância quando certas marcas linguísticas discursivas se repetem tendendo a construir um significado predominante.

As categorias de ressonâncias discursivas apresentadas a seguir englobam as categorias descritas por Serrani-Infante (2001) e as subcategorias criadas por Reis (2007): ${ }^{8}$

a. repetição de itens lexicais de uma mesma família de palavras;

b. repetição de itens de diferentes raízes lexicais apresentados no discurso como semanticamente equivalentes;

c. repetição de construções que funcionam parafrasticamente;

d. modos de enunciar presentes no discurso:

a. modo determinado e modo indeterminado de enunciar;

b. modo de definir por negações ou afirmações modalizadas ou categóricas;

\footnotetext{
${ }^{8}$ Serrani-Infante (2001, p. 40) propõe apenas três categorias das repetições, a saber, a) itens lexicais de uma mesma família de palavras ou itens de diferentes raízes lexicais apresentados no discurso como semanticamente equivalentes; b) construções que funcionam parafrasticamente; c) modos de enunciar presentes no discurso (como o modo determinado e o modo indeterminado de enunciar; o modo de definir por negações ou por afirmações modalizadas ou categóricas, modo de acréscimos contingentes utilizando incisas, glosas etc.). Porém, com base em Reis (2007), utilizamos uma subcategorização no intuito de facilitar a operacionalização de suas categorias.
} 
c. modo de acréscimos contingentes por meio de incisas e de glosas.

Os resultados obtidos a partir dos instrumentos de coleta utilizados nessa pesquisa são apresentados e discutidos a seguir.

\section{RESULTADOS E DISCUSSÃO}

\section{Impactos e desdobramentos da utilização do teatro e suas técnicas para a aprendizagem da língua inglesa}

Como já mencionado, Maley e Duff (1982) salientam que o uso do teatro favorece não apenas a aquisição de vocabulário, mas também a motivação e a autonomia do aluno. Os relatos a seguir, escritos por uma mesma aluna (S.D), em momentos distintos da intervenção, corroboram os resultados desses autores:

1. Mais uma aula excelente, realizada com a participação e envolvimento de todos. Aconteceram momentos de diversão como a realização das atividades e de aprendizagem. Os pontos positivos são a organização e o planejamento das aulas que fazem com que elas aconteçam e se superem cada dia. O ponto negativo; é uma questão particular por eu ainda não conseguir compreender todas as falas em inglês, o que sempre é traduzido em falas. (Relato de S.D. sobre a aula 2)

2. (...) Durante o encontro me senti mais segura e consegui ter mais concentração. Durante as atividades pude observar que consigo ouvir com mais atenção entendendo melhor as palavras. Aprendi novas palavras como pronunciá-las. Aprendi também a "observar" melhor e me concentrar mais. (Relato de S.D. sobre a aula 6)

3. Aprendi a ter mais atitude com a língua. Ou seja, me expressar, ou melhor, falar mesmo que pequenos textos, pequenos diálogos, na língua inglesa e que através de pequenos exercícios diários podemos aprender muito mais. (...) (Relato final de S.D.)

Além de citar a capacidade que a ferramenta metodológica tem de convocar os alunos para a construção de todos os eventos que se desenrolam na sala de aula ("uma aula excelente, realizada com a participação e envolvimento de todos"), a aluna S.D demonstra seu processo de amadurecimento com relação à língua inglesa, sua aprendizagem e sua forma de posicionar-se. Percebemos, por exemplo, o dizer de um progresso na aquisição vocabular e na compreensão da língua inglesa ("por eu ainda não conseguir compreender todas as falas em inglês"; "Durante as atividades pude observar que consigo ouvir com mais atenção entendendo melhor as palavras. Aprendi novas palavras como pronunciá-las.”), e, mais importante, vislumbramos a descoberta da aluna de um deslocamento que provoca um novo posicionamento diante da LI e da sua 
aprendizagem: "Aprendi a ter mais atitude com a língua. Ou seja, me expressar, ou melhor, falar mesmo que pequenos textos, pequenos diálogos, na língua inglesa".

Do mesmo modo, destacamos que, por mais dinâmica que a abordagem para o ensino da LE seja, o processo de aprendizagem pode trazer consigo algo que faz com que o aluno se sinta assustado ou até mesmo ameaçado. Ao constatar no relato sobre a aula 2 que a aluna se sentiu "mais segura" e conseguiu "ter mais concentração", apreendemos - por meio da análise do uso do advérbio de intensidade 'mais' - que S.D vivenciava, até aquele momento, momentos de insegurança e de falta de concentração. Notamos, nesse relato, traços que podem nos fazer vislumbrar incertezas e angústias no processo de aprendizagem da LI, que podem ser vencidos à medida que o aluno se abre às possibilidades da abordagem, com seus riscos e demandas, que podem fazer com que o aluno se sinta 'mais': mais seguro, mais concentrado, mais capacitado.

Ao mesmo tempo, os resultados também nos permitem afirmar que o ensino da LI por meio do teatro contribui para a formação ou fortalecimento do senso de responsabilidade e de cooperação entre os alunos, já que as atividades corporais, vocais, com texto, música ou de improvisação são realizadas em grupos com papéis definidos, exigindo uma participação ativa de todos os envolvidos (EARLY; TARLINGTON, 1983; MORDECAI, 1985).

Fernandez e Coil (1986) afirmam que o teatro encoraja o aluno a exercitar sua sensibilidade e emoção, tornando, portanto, a aprendizagem mais realista e significativa. Como um instrumento educacional, o uso do teatro, conforme nosso estudo indica, provoca o desenvolvimento social, intelectual e linguístico do aluno (DOUGILL, 1987). Nos relatos a seguir, verificamos, mais uma vez, o movimento progressivo do aluno com esse método. Do mesmo modo, os recortes a seguir salientam o impacto dessa abordagem para o desenvolvimento linguístico, social e subjetivo dos participantes.

4. Em minha opinião, o curso foi muito positivo em diversos aspectos. A interação entre os alunos foi benéfica para a prática da língua inglesa, bem como para a inicialização na área do teatro. As aulas eram mescladas em português e inglês, fato que facilitava a compreensão geral por parte dos alunos. O curso atuou em meus aprendizados básicos na área do teatro e aperfeiçoou as habilidades na língua inglesa. Além disso, os momentos de aula foram prazerosos e benéficos à melhora da postura e expressão corporal, auxiliando na autoconfiança para falar a língua e atuar no teatro sem vergonhas ou insegurança. (Relato final de S.C 
5. A meu ver a aula de hoje foi muito proveitosa. Achei muito interessante o trabalho com o corpo e fato de se sentir, de se conhecer e o trabalho feito em quarteto, onde falamos um pouco sobre nós. Devido a minha enorme dificuldade com o inglês, não consegui compreender muito bem algumas frases, mas no mais gostei muito. (Relato de K.P. sobre a aula 1)

6. A meu ver o curso de teatro em inglês foi uma experiência muito gratificante. Como já havia compartilhado no último encontro, tive contato com o teatro em outro momento, mas muitas atividades e dinâmicas vistas nesse curso foram novas pra mim. Nunca pensei que fosse possível relacionar teatro e inglês dessa forma. Sempre tive muita dificuldade com a língua inglesa (...). No início tudo era muito novo pra mim. Tive muita dificuldade para executar as atividades que envolviam o inglês, principalmente as que envolviam o diálogo. Porém, com o tempo o grau de dificuldade que eu tinha foi diminuindo e eu fui me sentindo mais a vontade e me soltando mais. Passei a me envolver melhor nas atividades. (Relato final de K.P.)

7. O curso Inglês via teatro foi muito bem ministrado, com aulas dinâmicas e diferentes. Em minha opinião, é um curso excelente que me acrescentou diferentes conhecimentos na língua inglesa, principalmente em relação a linguagem oral. Além disso proporcionou-me vivenciar experiências inéditas relacionadas ao mundo do teatro que outrora não conhecia. As aulas eram extremamente agradáveis, então tenho que confessar que por vezes, no "corre corre" do mundo universitário com provas e mais provas, considerei que dia de aula de inglês era dia de esquecer os problemas em casa, e relaxar, incorporar um personagem, simplesmente ser quem eu quisesse ser. Agora tenho sentido falta das minhas quartas-feiras, mas fico feliz em saber que fiz o meu melhor e fui até o fim. Aprendi palavras novas na língua inglesa, aprendi que não posso ter medo de errar, aprendi a trabalhar com improvisações e principalmente a trabalhar em grupo com pessoas que nunca tinha visto antes, enfim, valeu a pena! (...). (Relato final de K.O.)

Por meio dos relatos apresentados, podemos destacar o valor da aprendizagem que se constitui a partir da interação com o outro, da necessidade de comunicar, de se fazer compreendido e de executar alguma ação, sendo esses os objetivos essenciais do uso da língua. Esses relatos nos permitem inferir que o aperfeiçoamento das habilidades linguísticas dos participantes da pesquisa deu-se, principalmente, à medida que precisavam da língua-alvo para atingir objetivos reais, por meio da interação com o outro. Improvisos ou textos previamente estabelecidos possibilitaram que o aluno mergulhasse na experiência de (se) dizer em outra língua com todas as suas limitações, mas também com uma nova capacidade de reinvenção, conforme K.O nos aponta no relato 7: "considerei que dia de aula de inglês era dia de esquecer os problemas em casa, e relaxar, incorporar um personagem, simplesmente ser quem eu quisesse ser".

Com base em Revuz (1998), entendemos que o sujeito tem a oportunidade de descobrir outras formas de se ver e dizer no mundo por meio da aprendizagem de línguas. A partir do relato 7 de K.O, percebemos que, com o teatro, essa experiência de 
reinvenção (de si) torna-se não apenas uma demanda ou um requisito da metodologia, mas também uma estratégia para vivenciar a (aprendizagem da) língua. Corpo e língua revelaram-se indissociáveis e importantes para que os participantes aprendessem que arriscar e errar são partes indispensáveis do processo de aprendizagem. Assim, corpo e língua mesclam-se na constituição de uma instigante e desafiante possibilidade de ensino.

Outros benefícios do uso do teatro na aula de LI são relatados a seguir por diferentes participantes ao final do curso:

8. O curso foi muito bom, além de proporcionar ensinamentos na parte de artes cênicas, ajudou muito na dicção das palavras na língua inglesa, aperfeiçoando assim a minha pronúncia. $O$ curso atuou na minha vida ajudando a trabalhar na minha timidez e na minha concentração (...). Aprendi a me soltar mais, principalmente na fala da língua inglesa, consegui sentir mais firmeza. Gostaria muito de continuar, pois gostei muito do modo de ensino. (Relato final de F.B.)

9. No começo foi um pouco estranho, mas depois nos acostumamos ás atividades os exercícios do começo da aula como os aquecimentos nos relaxam e ajudam na concentração que seria necessária para a atividade a seguir. As quartas passaram a ser esperadas com ansiedade, agora fico me perguntando o que fazer depois de conhecer um método de ensino tão bom, como voltar ao comum? (Relato final de Y.M.)

10. A contribuição que o curso teve na minha aprendizagem foi muito benéfica porque uniu duas coisas do qual eu gosto muito: teatro e inglês. Deu-me mais forças para continuar a amar a língua inglesa porque incorporávamos cenas de filmes, percebi que o teatro que eu havia feito há alguns anos atrás também serviram para me ajudar agora também. Me incentivou a exercitar a expressão oral da língua estrangeira. (Relato final de Y.S.)

Além do progresso das habilidades linguísticas dos envolvidos por meio da intervenção e do trabalho com a timidez, a concentração e a segurança dos alunos, os relatos nos informam o modo como o aluno compreendeu ou assimilou a metodologia que envolve inglês e teatro. Tal experiência foi recebida pelos participantes como novidade que os convoca a unir, a seu processo de aprendizagem da LI, seu corpo e todas as suas emoções na formulação de uma instrução formal que se difere dos métodos e abordagens mais comumente encontradas, conforme Y.M questiona no relato 9: "As quartas passaram a ser esperadas com ansiedade, agora fico me perguntando o que fazer depois de conhecer um método de ensino tão bom, como voltar ao comum?". 
Além dos relatos, são também analisadas as entrevistas iniciais comparando-as com as entrevistas finais.

\section{Entrevistas iniciais versus entrevistas finais (Grupo Focal)}

Como explicitado na seção de metodologia, o aluno deveria atribuir uma nota para sua proficiência em língua inglesa (de 0 a 5), no momento da entrevista inicial (EI) e da entrevista final (EF).

Nas Entrevistas Iniciais (EIs), percebemos que alunos que se atribuíam uma nota de 0 a 2 alegaram ter contato com a aprendizagem da LI primordialmente nos ensinos Fundamental e Médio. Esses alunos apresentavam grande limitação linguística; eles eram capazes de dizer poucas e isoladas palavras em LI, não compreendiam as perguntas feitas em LI e recorriam sempre ao uso do português para expressarem-se. Em contrapartida, os alunos que consideravam seu nível de proficiência entre 3 e $4^{9}$ arriscavam mais no uso da LI, mesmo com muitas hesitações e receio de não falar corretamente. A maioria desses alunos alegou ter contato com a LI em cursos particulares, em músicas, jogos ou séries. O Gráfico 1 consolida os resultados de todas as notas atribuídas pelos alunos.

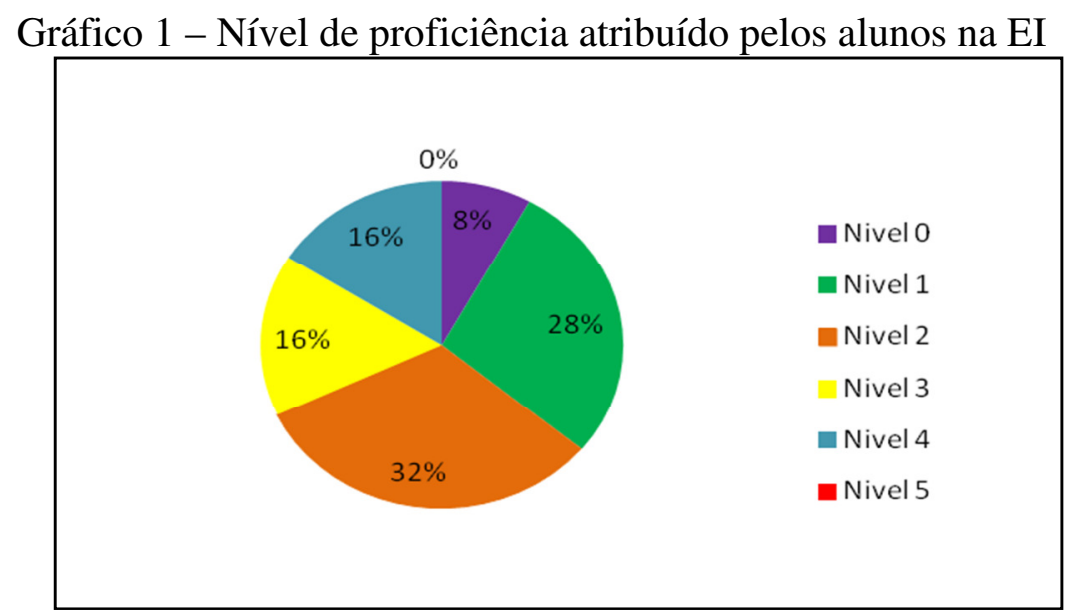

Fonte: Elaborado pelos autores.

Nesse gráfico, constatamos que $8 \%$ dos entrevistados no início do curso afirmaram não ter qualquer conhecimento da LI. Esses sentiram-se intimidados com o curso e evadiram no primeiro encontro. $60 \%$ dos alunos que fizeram a EI afirmaram estar um nível básico 1 ou 2, e 32\% dos alunos consideraram estar entre os níveis 3 e 4.

\footnotetext{
${ }^{9}$ Nenhum aluno se atribuiu nota igual a 5 na EI.
} 
Nas Entrevistas Finais (EFs), percebemos que aqueles alunos que anteriormente haviam considerado seu nível de proficiência entre 1 e 2 foram movidos pela ousadia de tentar e conseguiram trabalhar suas dificuldades até o final do curso, declarando e demonstrando avanço em seu desenvolvimento linguístico e atribuindo a si um nível acima em sua proficiência em LI. Os alunos que se atribuíram notas entre 3 e 4 na EI também afirmaram ter melhorado sua proficiência linguística, atribuindo nota 5 para sua proficiência linguística na EF. Esses resultados são consolidados por nível no Gráfico 2:

Gráfico 2 - Nível de proficiência atribuído pelos alunos na EF

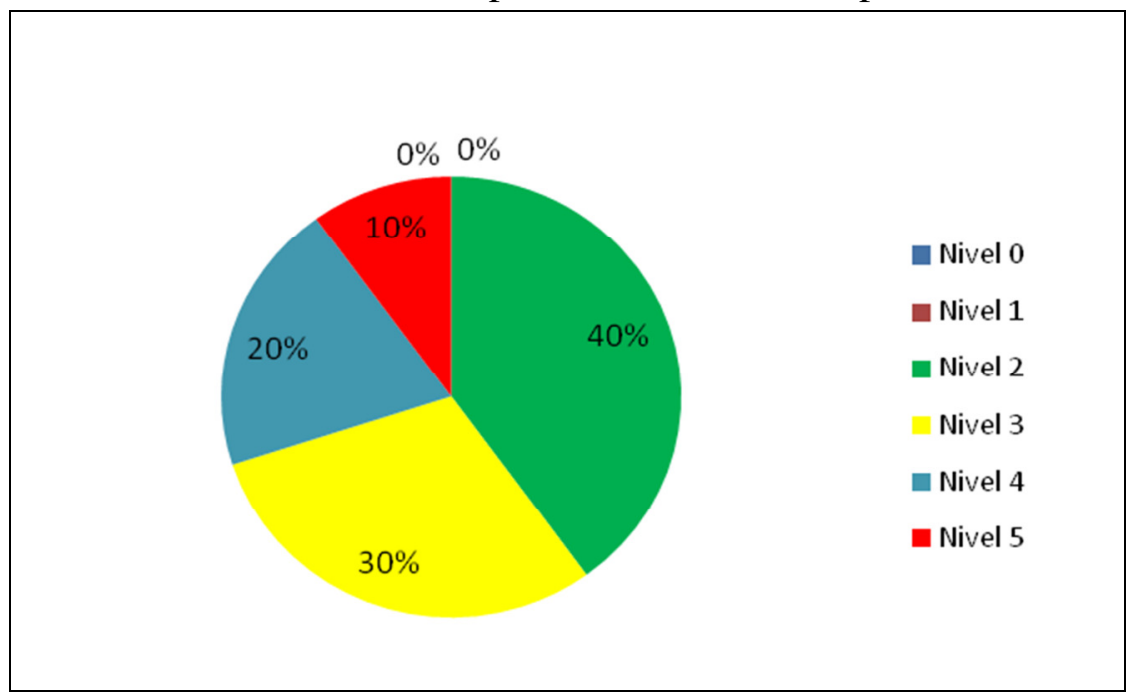

Fonte: Elaborado pelos autores.

Quando indagados se o curso contribuiu de alguma forma para sua proficiência linguística, 90\% dos alunos concluintes do grupo focal afirmaram que sim. Analisando a transcrição das entrevistas inicial e final desse grupo, foi possível perceber uma melhora na pronúncia dos alunos e uma significativa melhora lexical e sintática. Contudo, a maior e mais evidente contribuição que o teatro proporcionou para esses alunos reside no aumento da coragem dos alunos de se arriscar a falar, tentar compreender e se fazer compreendido, enfrentando suas limitações, perdendo o medo de usar a LI e rompendo enfim com (antigas) amarras.

Além disso, nas respostas das entrevistas finais, houve melhora na formulação de frases inteiras, redução no número de hesitações ou pausas longas, além de menos uso da língua portuguesa. Consoante a metodologia de ensino utilizada no curso, os alunos eram levados a explorar as quatro habilidades linguísticas, interagindo durante os encontros, lendo textos em LI, redigindo pequenos textos para improvisações e 
finalmente interpretando na língua-alvo, $o$ que parece ter influenciado $o$ desenvolvimento linguístico dos participantes. A mudança na produção linguística de alguns dos participantes dos grupos focal e controle pode ser visualizada nas transcrições das entrevistas inicial e final apresentadas no Quadro 1:

Quadro 1 - Entrevistas inicial e final do grupo focal

GRUPO FOCAL: G.D.

\begin{tabular}{l|l} 
EI & EF \\
\hline
\end{tabular}

E: Who are you? Tell me about yourself.

Hum // // I'm cool // hum // and / a good friend / I liki // // I like // // [what do you do in your free time?] / taekwondo [E] Blues and (xxx) [risos] /

\section{$\mathrm{EF}$}

\begin{tabular}{|c|c|}
\hline [E] Blues and (xxx) [risos] / & $\begin{array}{l}\text { the small city / in Minas Gerais /São João } \\
\text { Evangelista // I like / I like hun marcial } \\
\text { arts / I Love taekwondo / and my my } \\
\text { dream is / travel to Korea / South Korea } \\
\text { and up my skills in taekwondo. [What do } \\
\text { you do in your free time?] / Free time? / I } \\
\text { play guitar / and talk with my friends / } \\
\text { with my / my house friends / I live with } \\
\text { six friends / it's a big house / and I like } \\
\text { room and cook / I'm::: / I'm make pizza } \\
\text { and // I make \% cake. }\end{array}$ \\
\hline \multicolumn{2}{|l|}{ GRUPO FOCAL: K.O. } \\
\hline EI & $\mathrm{EF}$ \\
\hline \multicolumn{2}{|l|}{ [E]: Talk about a person in your family? } \\
\hline $\begin{array}{l}\text { My brother / have // twent twenty/ } \\
\text { years / he study in /anh / computer // he } \\
\text { w\%ork in /v ery good // He // // Ele tem } \\
\text { muito talento para computador [risos]. }\end{array}$ & $\begin{array}{l}\text { Hum / I have one brother/ my } \\
\text { father and my mother uhm / live in ::: Belo } \\
\text { Horizonte / hum / hum // // [talk about } \\
\text { one of them] / my brother / my brother // } \\
\text { have / twenty one years old / studying in // } \\
\text { // study computer / in U UFMG // // } \\
\text { [risos] }\end{array}$ \\
\hline
\end{tabular}

Fonte: Elaborado pelos autores.

Por outro lado, nas transcrições do grupo controle apresentadas no Quadro 2 abaixo, podemos observar que o aluno P.M. não compreendeu a pergunta feita pelos pesquisadores, além de demonstrar ter dificuldades consistentes para formular as respostas na EF: 
Quadro 2 - Entrevistas inicial e final do grupo controle

\section{GRUPO CONTROLE: P.M}

EI EF

E: Who are you? Tell me about yourself.

// [você perguntou como que eu vou?] /[E] / My name is P./I have twenty four years old/I li\%ve in Diamantina/Minas Gerais/[E] Yes/[E].
/ Heee//[ Aluno mostra dúvida] /heee/I'm.../I'm \% student// [E]/Yes/I / I like travel/ heee/watch TV/ study english/but//sair!? com friends/[E]/go out friends//about!

E: Talk about a person in your family?

[Aluno: o percentual de inglês na minha família?!]/ [E]/[aluno ainda não entendeu a pergunta]/[Aluno: falar sobre o que?]/[E]/my mother/+ she is//[E] /quarenta e seis/[E] // a vida dela é só trabalhar[risos]/coitada/oh meu Deus/ $[E] /$ Ela trabalha fixo num motel/[E]/yes// adoro ela [risos]. [E: Do you has brothers and sisters?]/ Yeah/

\section{GRUPO CONTROLE: M. F} EF

E: Who are you? Tell me about yourself.
I: Yes! My name is/ M. / I am thirty years/old/+thirty years old/ I I am undergrate of letters/I am a \% teacher/and/I am married/with/M./ He is deficient/and and I live in Diamantina and one years and /four months[aluna fala quase cantando essa última frase]so full [risos] and I study letters because I I\%I think the language/very beautiful. I I \%like to study languages/eee/I studied//in ::: two thousand six/ [aluna repete a frase com mais firmeza] two thousand six!? Anhh the [não entende-se a palavra que ela disse] for fiv for four months/ very good too/is a language very good/and I/\% I have so many plaining/ Here in Diamantina I am in a teacher but /eeee/the//[murmúrios pensativos] remuneration/is very bit [risos]I hav' only seven and classes/and the [murmúrios] in the// my profission my profission my/[murmúrios][mais murmúrios E:Do you have a children?]

\section{EF}

Talk about :::?/ [E]/hummm/// my primors??/[E]/cousin/heee/live in exterior/mora/[E]/eeee/Holanda/[E]/no/[E] / heee/ I'm /I'm /primo?/[E]/cousin in Austria/[risos]/very good/[risos]/no/no. $\mathrm{Hum} / \mathrm{I}$ am a/that some that/ live so
tired/actually/but I I I feel/ so happy/because I had I :::

am/ I hav I have ::: had/I had a little having/so many opportunities/eee/in the university/ and in my Professional life/ humm/ I am trying to study/and to be a housewife/[risos]/and to be a to be a /undergraduating/and I am happy because I/ will see my family.[E] Yes/[E]Yes./me and my husband/and my/dog/little dog/[E]Yes.[E] half pass/ twelve/ If I [fala incompreensível /falou muito baixo]. \% no, no [murmúrios difíceis de entender na língua portuguesa/ desconexos e baixos] fifteen past/[murmúrios]. 
no, I don't.

E: Talk about a person in your family?

My mother/my mother/ she is a woman very simple/and she makes me to study/and she was/eee/ [fala imcompreensível] and/she studied until four th year/fourth year/and she has fifthy five/fifth seven years/she is very funny/but she has so many problems of the married woman/we broke a passion/my $\mathrm{dad} /$ because the/so/because the woman/ the woman a very [murmúrios] /they don't have a long/[murmúrios] relachionship/ and my mother/suffered because/ my dad/some many times/ sometimes/lays others woman/[E] and she is/sad these day/because it's very difficult/and I/I I/I from/I lived/I was born in São Luis do Maranhão/ [E]/and when I called/ to her/she saids/she cries/and is very $\%$ difficult to me/to stay here wanting to stay there [E] yes/I am/yes/I have four/two brothers/and two sisters/[conversa em portuguÊs][risos][E] Here in Diamantina/I come/to work/and I lived in Minas Novas/two years/because I married/with my husband/[E] /I marry on th+ree three years ago/in February I /I will make four years.

Fonte: Elaborado pelos autores.

Ao contrário do que esperávamos, a EF da aluna M.F., do grupo controle, foi mais limitada na EF do que na EI. Após quase quatro meses de curso com o grupo focal, e já ao final do semestre letivo dos alunos do grupo controle, a aluna M.F parece não ter se beneficiado de seu curso regular (Língua Inglesa II), uma vez que não pudemos perceber mudança no seu desempenho linguístico. De um modo geral, a análise das entrevistas realizadas com o grupo controle, matriculados na disciplina Língua Inglesa II, e não nas aulas de inglês com técnicas teatrais, não nos permite apontar avanços lexicais, sintáticos ou semânticos na produção linguística dos alunos. Assim, defendemos que a intervenção em sala de aula de língua inglesa com o uso de teatro e suas técnicas parece ter um papel importante na aprendizagem de inglês e na constituição do sujeito dessa prática. 


\section{CONCLUSÕES E PERSPECTIVAS}

O ensino do inglês com uso do teatro e de suas técnicas demonstrou uma boa aceitação pela comunidade acadêmica e externa, tendo em vista que 18 dos 28 alunos inscritos concluíram o curso. Mais que isso, essa perspectiva de ensino revelou-se um valioso instrumento ao promover não apenas o desenvolvimento linguístico do aluno, mas também o desenvolvimento de aspectos da subjetividade do participante.

Retomando as perguntas que orientaram o presente estudo, identificamos que a metodologia utilizada impactou não somente a proficiência do aluno, mas principalmente seu modo de se colocar diante da LI, sua aprendizagem e ao modo como ele se constitui. O deslocamento linguístico dos alunos foi positivo, indicando avanço de um nível acima do que tinham antes de participar do curso. Esse índice é relevante ao considerarmos o curto tempo em que foram ministradas as aulas semanais (15 encontros) com três horas de duração. Assim, os exercícios de interpretação, as dinâmicas, as leituras, os vídeos, as músicas, os ensaios e as apresentações fizeram com que os envolvidos melhorassem seu nível linguístico de forma abrangente.

Muitos alunos de cursos de línguas focam tanto na aprendizagem e no uso de regras gramaticais que temem o erro e não conseguem desenvolver a habilidade oral. $\mathrm{O}$ uso das técnicas teatrais foi um sistema revelador para esse perfil de aluno, pois o levou a aprender praticando, com suas tentativas, acertos e erros. Desse modo, o aluno era jogado em cena, e a partir de uma situação, criava-se a necessidade do uso do corpo, da voz, da LI para resolver problemas ou conflitos. O aluno simplesmente comunicava-se, sem amarras e pela genuína necessidade de (se) dizer.

Podemos afirmar, portanto, que, no início da abordagem, os alunos mostravamse recolhidos e temerosos, e o teatro com o uso de diferentes dinâmicas permitiu uma redução acentuada da timidez e do medo de usar a habilidade linguística comumente apontada como a mais difícil: a fala na comunicação interpessoal. Nas palavras do aluno J.L, do grupo focal, em sua entrevista final, resumimos o modo como essa experiência foi significada pelo participante da pesquisa:

11. (...) no começo eu tinha medo de falar inglês / eu tenho as coisas na cabeça mais as vezes eu não sabia juntar as palavras para falar (...) Eu perdi o medo / por exemplo / eu notei / como eu sabia do corpo / de pular / desses trem tudo / eu / ler música hoje em dia tá muito mais fácil para mim / eu já faço inglês mas tipo assim / eu acho que a gente nunca pegou o inglês tão firme assim como / eu percebi que no começo eu tava assim / nossa / e 
outras vezes que você começava a falar no final eu já entendia tudo / então assim / eu acho que a gente perdeu o medo mais no inglês e / por causa de expressão corporal / assim / como não era só eu que não sabia muito o inglês / todo mundo tava no mesmo barco / (...) (JL)

Percebemos que o ensino-aprendizagem da LI juntamente com o teatro fez com que os alunos concluintes do curso compreendessem que o corpo, os gestos e as encenações artísticas são grandes auxiliadores no desenvolvimento de seu nível linguístico integral. O contato com o outro não é inibidor, mas sim um estímulo para o desenvolvimento e estudo sério e engajado, mesmo diante de uma aparente descontração.

A compreensão do papel do corpo, dos movimentos, da entonação da voz para a constituição da linguagem e da expressão de si fez com que os alunos ganhassem autonomia e coragem em sua aprendizagem. Desse modo, não apenas palavras foram aprendidas, ou a capacidade linguística do aluno ampliada, mas houve, sobretudo, espaço para que a constituição subjetiva do participante fosse redefinida.

Explorar as particularidades de cada novo personagem interpretado tornou-se um importante instrumento para os alunos, à medida que eles perceberam o poder da linguagem que se desenvolve para além do 'simples' uso das palavras. Com isso, os alunos revestiram-se de coragem e segurança para enunciar na LI, colocando-se em cena e trabalhando de forma ativa e efetiva para o desenvolvimento de sua habilidade linguística.

A possibilidade de o aluno "tornar-se um outro" (REVUZ, 1998) constantemente permitiu que ele se descobrisse de formas diferentes. Muitas vezes, a vontade de ir além do habitual surge do que vivenciamos ao sermos tocados de forma singular pelo outro ou ao sermos colocados no lugar do outro. As técnicas teatrais como uma arte primitiva trazem consigo uma carga de sabedoria e conhecimento cultural adquirido em séculos. É a arte do ser um outro, sem deixar sua própria vida, mas reescrevê-la de algum modo repensando e redefinindo sua subjetividade. A língua também traz a mesma ancestralidade e o mesmo poder de tocar o outro, de fazer com que o sujeito descubra-se um outro e reescreva sua própria história. Por isso, defendemos que o uso do teatro a favor do ensino de línguas pode ser enxergado como um método promissor.

Defendemos, por fim, que mais estudos sejam realizados para que possamos aprofundar a compreensão do modo como o teatro e o ensino de línguas podem encontrar-se para a 
formulação de uma metodologia que toca tanto aspectos linguísticos, quanto aspectos subjetivos do aprendiz envolvido. Como a presente pesquisa foi realizada com um número reduzido de alunos, em um tempo reduzido e com um grupo oriundo de outros cursos e tarefas, o que pode ter limitado os resultados do estudo, a proposta pode servir de base para elaboração de uma investigação que ocorra durante todo um semestre ou ano, a fim de detalhar ações e potencializar resultados. Desse estudo mais amplo, poderia ser desenvolvido, testado e, então, divulgado, rico e detalhado material didático aos interessados em promover o ensino de línguas por meio do teatro. Esperamos, desse modo, que tal metodologia possa desenvolver-se e alcançar ou expandir seu espaço pedagógico, para que enfim antigas amarras que emperram a aprendizagem de línguas estrangeiras de alguns alunos sejam finalmente desatadas e (novos) deslocamentos linguísticos e subjetivos sejam contemplados.

\section{REFERÊNCIAS BIBLIOGRÁFICAS}

ALIAKBARI, M.; JAMALVANDI, B. The Impact of 'role play' on fostering EFL learners' speaking ability: a task-based approach. Journal of Pan-Pacific Association of Applied Linguistics, v. 14, n. 1, p. 15-29. 2010.

ALMEIDA FILHO, J. C. P. Dimensões comunicativas no ensino de línguas. Campinas, SP: Pontes, 1993.

BORK, A. V. B. Aprendizagem de língua inglesa no ensino médio: um estudo empírico com a técnica de dramatização. 198f. Dissertação de mestrado. Universidade Federal do Paraná. 2005.

BOUDREAULT, $\mathrm{C}$. The benefits of using drama in the ESL/EFL classroom. The Internet TESL Journal, Vol. XVI, No. 1, January 2010.

COÊLHO, M. A. B. As oficinas de teatro no processo de ensino e aprendizagem e na formação dos professores de língua inglesa: um estudo " $q$ ". 133f. Dissertação de Mestrado. Universidade Federal de Uberlândia. 2010.

CORACINI, M. J. Língua materna-estrangeira: entre saber e conhecer. In: CORACINI, M. J. (Org.). A celebração do outro: arquivo, memória e identidade. Campinas: Editora da Unicamp, 2007. p. 149-162.

CORACINI, M. J. F. A celebração do outro. In: CORACINI, M. J. F. (Org.). Identidade e discurso. Campinas: Editora da Unicamp; Chapecó: Argos Editora Universitária, 2003. p. 197-221. 
DINIZ, T. F. N. Ensino de inglês através de técnicas de teatro. In: PAIVA, V. L. M. de O. (Org.) Ensino de língua inglesa: reflexões e experiências. Campinas: Pontes, 1996, p. $115-122$.

DOUGILL, J. Drama activities for language learning. London: Macmillan, 1987.

EARLY, M.; TARLINGTON, C. Off stage: Informal drama in language learning. ELT Documents 113, 1982.

FERNANDEZ, L.; COIL, A. Drama in the classroom. Practical Teaching 6:3, p.18-21. 1986.

FIGUEIREDO, J. D. O paradigma do teatro moderno: novos rumos e novos conceitos. Disponível em: http://www.bocc.ubi.pt/pag/figueiredo-jorge-o-paradigma-do-teatro.pdf Acesso em: 05 de abril de 2014.

HANSTED, T. C.; GOHN, M. G. Teatro e educação: uma relação historicamente construída. EccoS, São Paulo, n.30, p. 199- 220. Jan./abr. 2013.

HOLDEN, S. Drama in language teaching. Longman handbooks for language teachers. London: Longman Group Limited. 1981.

ISLAM, P.; ISLAM, T. Effectiveness of role play in enhancing the speaking skills of the learners in a large classroom: An investigation of tertiary level students. Stamford Journal of English; Vol. 7, p. 218-233. 2012.

KAO, S. Words into worlds, learning a second language through process drama. Stamford, USA: Ablex Publishing corp. 1998.

KUMBARTZKI-FERREIRA, J. The effects of role-play tasks on EFL learners oral fluency. 198f. Dissertação de mestrado. Universidade Federal de Santa Catarina, Centro de Comunicação e Expressão. Programa de Pós-Graduação em Letras/Inglês e Literatura Correspondente. 2008.

LIVINGSTONE, C. Role-play in language learning: Longman handbooks for language teachers. Singapore: The Print House Ltd, 1983.

MALEY, A.; DUFF, A. Drama techniques in language learning. Cambridge: Cambridge University Press,. 1982.

MENEZES, M. D.; COSTA, R. D. F.; JUNIOR, V. J. S. Theatre in the classroom: $o$ aprendizado por meio da arte. VI Colóquio Internacional: "Educação e Contemporaneidade". São Cristovão, SE, 20 a 22 de set, 2012. Disponível em: http://educonse.com.br/2012/eixo_09/PDF/20.pdf . Acesso em 01 de junho de 2014.

MESKELL, A. G.; SANDER, L. V. O teatro como instrumento no ensino de uma língua estrangeira. Educação, Brasília, v. 5, n. 20, p. 72-79, abr. jun. 1976.

MORAES, K. A. R. F. C. A percepção de aprendizes brasileiros de inglês sobre a tarefa role-play como estratégia de desenvolvimento da oralidade. 211f. Dissertação 
(Mestrado em Programa de Pós-Graduação em Letras) - Universidade Federal do Paraná. 2014.

MORDECAI, J. Drama and second language learning. Spoken English, 18:2, p.12-15. 1985.

OLIVEIRA, E. A; FARIAS, C. C. A.; FARIAS, R. C. A utilização do teatro como prática pedagógica no ensino-aprendizagem da Escola Estadual Coronel Vanique, Município de Nova Xavantina-MT. Anais Vol. 2 (2013): Seminário PIBID UNEMAT, Cáceres/MT, Brasil, 22-24 abril 2013, Pró-Reitoria de Ensino de Graduação - PROEG, Universidade do Estado de Mato Grosso - UNEMAT.

REIS, V. S. O Diário de Aprendizagem de Língua Estrangeira (Inglês) sob a perspectiva do Processo Discursivo. 143p. Dissertação (Mestrado em Estudos Linguísticos) - Programa de Pós-Graduação, Universidade Federal de Minas Gerais, Belo Horizonte, 2007.

REVUZ, C. A língua estrangeira entre o desejo de um outro lugar e o risco do exílio. Trad. de S. Serrani-Infante. In: SIGNORINI, I. (Org.). Lingua (gem) e identidade. Campinas: Mercado de Letras; São Paulo: Fapesp, 1998. p. 213-230.

RICHARDS, J. Conversational competence through role-play. RELC Journal, vol. 16, n. 1, p.82-100. 1985.

SAM, W. Y. Drama in teaching English as a second language: a communicative approach. The English Teacher, v. 19, p. 1-11, 1990.

SANTANA, A. P. Trajetória, avanços e desafios do teatro-educação no Brasil. Disponível em: http://www.uesb.br/evidencias/2014/01/fase-2-teatro/texto04.pdf. Acesso em: 09 de abril de 2014.

SERRANI-INFANTE, S. M. Ressonâncias discursivas y cortesia em prácticas de lectoescritura. D.E.L.T.A., São Paulo, v. 17, n. 1, p. 31-58, 2001.

SOUZA, J. C. B. O texto dramático: uma ferramenta para desenvolver a apropriação em LE. Dissertação de Mestrado. 125 f. Departamento de Línguas Estrangeiras e Tradução. Universidade de Brasília, 2013.

TAVARES, R. O jogo teatral na sala de aula. In: MACHADO, I.; TELLES, N.; MERISIO, P.; MEIRA, R. B. (Org.). Teatro, ensino e prática. Uberlândia: EDUFU, 2004. p. 41-49.

WHITESON, V. New ways of using drama and literature in language teaching. In: Richards, J. C. (Ed.), New ways in TESOL series II: Innovative classroom techniques, Bloomington, IL: TESOL, Inc. 1996. 
ANEXOS

\section{ANEXO 1}

\begin{tabular}{|l|l|}
\hline \multicolumn{2}{|c|}{$\begin{array}{c}\text { Convenção } \\
\text { Marcas Prosódicas }\end{array}$} \\
\hline$/ /$ & Pausa \\
$/ / /$ & Pausa Longa \\
$/ / / /$ & Pausa muito longa \\
$\%$ & Mais de 20 segundos de pausa \\
+ & Aumento da entonação \\
(xxx) & Queda da Entonação \\
[ ] & Fala Incompreensível \\
& Elementos da/para Contextualização / \\
$:::$ & comentários da pesquisadora \\
& Alongamento da vogal / Consoante / Palavra \\
E & Entrevistador \\
\hline & Informante \\
\hline
\end{tabular}

ANEXO 2

\section{Entrevista Inicial}

E: Who are you? Tell me about yourself. What do you like to do?

E: Talk about a person in your family?

E: What did you do in your last holiday?

E: What are you going to do in your next holiday?

E: What is your learning english history?

E: What will you be doing in ten years than now?

E: If you could be anyone in the world, who would you could be?

E: What is the most exciting thing that you ever done in your life? 
REVISTA X, Curitiba, volume 12, n.3, p.152-177, 2017.

\section{ANEXO 3}

\begin{tabular}{|lll|}
\hline & Aluno em Cena & \\
Relato & Nome: & Data: \\
\hline
\end{tabular}

a. Aprendeu alguma nova palavra ou expressão da língua inglesa hoje? Qual/Quais?

b. Comente a aula de hoje. Fale de suas impressões gerais. Pontos positivos e negativos. 